\title{
Identifying the Factors Affecting the Management of Addiction Treatment Clinics: A Qualitative Study
}

 \\ ${ }^{1}$ Department of Health Services Management, School of Medical Sciences and Technologies, Science and Research \\ Branch, Islamic Azad University, Tehran, Iran
}

\begin{abstract}
*Corresponding Author: Ali Komeili, M.D., Professor, Department of Health Services Management School of Medical Sciences and Technologies, Tehran Science and Research Branch, Islamic Azad University, Tehran, Iran. Tel: +98-2144867550, Email: komeili@srbiau.ac.ir
\end{abstract}

Received July 7, 2020; Accepted October 3, 2020; Online Published December 19, 2020

\begin{abstract}
Background: Due to the expansion of addiction treatment clinics and the costs that these clinics incur on the government and the families of addicts, monitoring the performance of these clinics and the need to pay attention to the principles of management, efficiency, and effectiveness is essential.

Objectives: The present study was conducted to identify the factors affecting the management of addiction treatment clinics.

Methods: The present study is a descriptive-applied and cross-sectional study conducted in 2019. Experts and academic experts have been considered as the research community, and 18 people were selected as the research sample by the purposeful snowball method. Data collection tools were the review of relevant national and international documents as well as semi-structured exploratory interviews. Finally, after collecting information from the interview sections and reviewing the sources, the data foundation and coding methods (open, axial, and selective) were used to classify the data.

Results: The findings of the study showed that the effective factors in the management of addiction treatment clinics are dimensions such as organization, planning, control, guidance as well as leadership and treatment management.

Conclusion: According to the findings of this study, it can be concluded that the effective factors in the management of addiction treatment clinics can be a good basis to evaluate managers so that the policies and programs of the organization can be upgraded, modified, and reviewed.
\end{abstract}

Keywords: Clinical Management, Addiction Cessation, Treatment Management

\section{Background}

Addiction to heroin and opium derivatives has become an epidemic in the modern world and a global phenomenon. Addiction is a phenomenon that knows no boundaries and is seen in all races and economic classes; in other words, it has become a way of life. ${ }^{1}$ Due to the problems and financial burden of addiction, new policies around the world focus on opioid-dependent drug treatment, and since 2010 the insurance industry has entered the mental health program and addiction clinics. ${ }^{2}$ From drug-related infectious and physical illnesses to high-risk drug-related behaviors and drug-related social ills (poverty, death, divorce, crime, child labor, prostitution) billions of dollars are spent on governments around the world each year.

Opium is the most common opioid in Iran, with $82 \%$ being the top illegal drug. The prevalence of opium use is $28 \%$, methadone for non-medical use is $16.6 \%$, heroin and concentrated heroin are $16 \%$, and morphine is $2.6 \%$ among addicts. Apart from opioids, common substances used illegally in Iran include alcohol with a prevalence of about $2 \%$ in 12 months in 2012, cannabis about $1 \%$, and methamphetamine about half a percent in 2011. However, in Iran, the focus is on the treatment of opioid dependence, and there are about 7000 outpatient clinics for methadone and buprenorphine maintenance treatment, which have a population of about 900,000. Maintenance therapy with opioid agonists, also known as methadone maintenance treatment (MMT), was first performed by two physicians, Vincent Dole and Marie Niswander, in New York City in $1964 .^{3}$

The main treatment regimen for quitting addiction, in addition to medication, included comprehensive rehabilitation and medical services for heroin injecting drug users. At that time, the criteria and standards to perform MMT in patients included four years of heroin addiction, a history of previous unsuccessful treatment, a desire to receive this type of treatment, age over 19 , early dependence on opioids, and no psychosis and major medical illness. ${ }^{3}$ In initial studies, addicts received daily doses of oral methadone in the hospital before being transferred to outpatient clinics for further treatment. With the passage of time and gaining more experience in

Copyright $(2) 2021$ The Author(s). This is an open-access article distributed under the terms of the Creative Commons Attribution License (http:// creativecommons.org/licenses/by/4.0), which permits unrestricted use, distribution, and reproduction in any medium, provided the original work is properly cited. 
MMT, the inpatient period of removal and treatment was performed directly in outpatient clinics. The therapeutic outcomes of the early years of MMT were favorable. ${ }^{3-5}$

MMT became widely used in most major US cities in 1970s. With the development of this treatment, changes were also made to the MMT treatment program. One of the most important and pervasive changes was the involvement of local, state, and federal governments in establishing new clinics, and in 1972 the Food and Drug Administration enacted laws on the type and amount of health care. ${ }^{6}$

The first step in a comprehensive plan to reduce demand in Iran dates back to the formulation of a "program for the prevention, treatment, and rehabilitation of substance abuse" in 1994 in the Welfare Organization. Since 1996, outpatient treatment centers for addicts or MMT have expanded rapidly to about seven thousand centers now. About three decades after the arrival of MMT treatment in Iran, many studies have been conducted on the effectiveness of this treatment in Iran. The first study was conducted in 2002 with financial support from the United Nations Office on Drugs and Crime. ${ }^{7}$

\section{Objectives}

In Iran, the low success rate of MMT imposes high costs on the community and the government for the treatment of drug-related illnesses and drug-related crimes which may indicate that the current management model of clinics and treatment process is not efficient enough and does not have the desired effect and, consequently, the low success rate of MMT in Iran is associated with a high rate of criminal activity and the resulting infectious diseases. Considering the lack of efficient management and the use of other rehabilitation services in this regard, the need to design an optimal management model increases a hundred times.

\section{Methods}

The present study is a descriptive-applied and crosssectional study conducted in 2019 to identify the effective factors in the management of addiction treatment clinics. Academic experts (university professors in the field of addiction) are considered as the research community who were selected by the purposeful snowball method. Conducting 18 interviews (ultimately the results of 15 interviews were used due to the duplication of some interview results), the data collection tool was a review of relevant national and international documents as well as a semi-structured exploratory interview. Finally, after collecting information from the interview sections and reviewing the sources, in this stage, the data foundation and coding methods (open, axial, and selective) were utilized to classify the data. Internal validity of the findings, in addition to the data being selected and confirmed by studying the theoretical foundations, research background, sources, interviews with focal individuals, the opinions and guidelines of a group of experts were taken into account and final coding was performed before coding.
To confirm the accuracy of the data, the study method was used by the research members to validate the study. To determine the external validity (transferability) of the findings, the techniques of theoretical saturation, special coding procedures, analysis of symbols and signs, and rich description of data were used.

\section{Results}

During the open coding phase, the followings were performed: the data were carefully examined, appropriate phrases and concepts, and related categories were identified, dimensions and features were determined, and the pattern was examined. Concepts were the main units of analysis for open and axial coding. While carefully analyzing the data, the concepts through titling by the researcher were created directly from the transcripts of the participants' interviews (live codes) or according to the common cases of their application. The transcribed interviews were examined regularly to find the main items, which resulted in a total of 125 open codes (items), and ultimately by removing some concept codes, 123 items in the form of 17 components and 6 dimensions were categorized.

Finally, after analysis and extracting the dimensions, components, indicators, and items, based on data-based method coding, the factors affecting the management of addiction treatment clinics in the form of 122 items in the form of 15 components and 5 dimensions were approved (Table 1).

\section{Discussion}

The low success rate of MMT in Iran has put high costs on the society, and government for the treatment of drug-related sicknesses, and drug-associated crimes, demonstrate that the common clinic management system and treatment process is ineffective. ${ }^{8}$ Moreover, it does not have the ideal effectiveness and, therefore, the low success rate of MMT in Iran is related to a high rate of criminal activity leading to infectious illnesses. In this respect, the demand to construct an ideal management system enhances a hundredfold. The high accomplishment estimate of MMT can indemnify large financial expenditure to the government. A unified, consistent, and regulated management system for addiction clinics can solve economic, social, and cultural problems policymakers and planners. ${ }^{9,10}$

During the coding step, some items were removed and some were added, and finally, 122 items were obtained in the form of 15 components and 5 dimensions. Findings of the study indicated that the identified dimensions for the management model of addiction treatment clinics are dimensions such as; organizing, planning, controlling, leading, and treatment management.

The two components of organizing human capitals and organizing structures and processes form the dimension of organizing. Three components of financial and economic resource management, physical and public resource management, information and knowledge 
Table 1. Dimensions, Components, and Indicators Obtained During Open and Axial Coding

\begin{tabular}{|c|c|c|}
\hline Dimensions & Components & Number of Items \\
\hline \multirow{2}{*}{ Organizing } & Organizing human capital & 19 \\
\hline & Organizing structures and processes & 8 \\
\hline \multirow{3}{*}{ Planning } & Management of financial and economic resources & 8 \\
\hline & Physical and public resource management & 4 \\
\hline & Management of information and knowledge resources & 7 \\
\hline \multirow{2}{*}{ Controlling } & Quality management & 7 \\
\hline & Process monitoring & 7 \\
\hline \multirow{5}{*}{ Leadership } & Health research and technology leadership & 8 \\
\hline & Crisis Management & 4 \\
\hline & Factors of accountability, satisfaction, and loyalty & 7 \\
\hline & Communication with the client and public relations & 9 \\
\hline & Service development & 4 \\
\hline \multirow{3}{*}{ Treatment management } & Manpower & 4 \\
\hline & Costs & 3 \\
\hline & Physical space & 3 \\
\hline
\end{tabular}

resources management, form the planning dimension. The control dimension is formed by the two components of quality management and process monitoring factors. In the field of leading, especially in medical organizations and MMT clinics, we can mention five important and effective components of research leadership and health technology including; crisis management and passive defense; accountability, satisfaction, and loyalty; communication with the client and public relations; and services development. Ultimately, the three components of manpower, cost, and physical space form the dimension of treatment management.

Etebarian et al designed a model of sustainable healthoriented development in three dimensions: social, environmental and economic, and concluded that the use of this model reduces the tendency to addiction. ${ }^{11}$ In general, Gholami ${ }^{12}$ considered management-physical

\section{Research Highlights}

\section{What Is Already Known?}

The tendency of the government and a part of the addicted community to employ addiction treatment clinics and the high rate of recovering addicted individuals succumb to relapse under the supervision of these centers compared to other countries doubles the need to review and adopt a scientific approach in the management of these centers to reduce harm.

\section{What Does This Study Add?}

The results of data-based coding led to the identification of 122 open-source codes, 15 core codes, and 5 selected codes. Findings indicated that effective factors in the management of addiction treatment clinics are the dimensions such as organization, planning, control, guidance as well as leadership and treatment management. design methods, cooperation, supervision of NAJA and welfare to be effective in preventing relapse to addiction. Also, reviewing and reforming policies is a way to improve the current state of addiction. ${ }^{13}$

\section{Conclusion}

According to the research findings, a total of 5 dimensions and 15 components were identified as an underlying factor in the form of effective factors in the management of addiction treatment clinics. Based on the same findings, the existence of a dry and inflexible hierarchy is one of the main reasons to disrupt the achievement of the goals of the centers. Therefore, planners and decision-makers in this area are advised to reconsider the structure of activities and try to move the system towards giving flexibility.

\section{Authors' Contributions}

Conceptualization: AK and LR. Data analysis: IA. Methodology: AK and SJT. Supervision: AK, LR and SJT. Writing the original draft: IA. Critical review and editing: AK, LR and SJT. All authors approved the final manuscript.

\section{Conflict of Interest Disclosures}

There was no conflict of interest in this research.

\section{Ethical Approval}

Current study was approved by Department of Health Services Management, Science and Research Branch, Islamic Azad University, Tehran, Iran.

\section{References}

1. Wang MP, Ho SY, Lo WS, Lam TH. Smoking family, secondhand smoke exposure at home, and nicotine addiction among adolescent smokers. Addict Behav. 2012;37(6):743746. doi:10.1016/j.addbeh.2012.02.016.

2. Ferguson CJ, San Miguel C, Garza A, Jerabeck JM. A longitudinal test of video game violence influences on dating and aggression: a 3-year longitudinal study of adolescents. 
J Psychiatr Res. 2012;46(2):141-146. doi:10.1016/j. jpsychires.2011.10.014.

3. Desrosiers A, Miller L. Relational spirituality and depression in adolescent girls. J Clin Psychol. 2007;63(10):1021-1037. doi:10.1002/jclp.20409.

4. Coward DD, Reed PG. Self-transcendence: a resource for healing at the end of life. Issues Ment Health Nurs. 1996;17(3):275-288. doi:10.3109/01612849609049920.

5. Barajas-Nava L. Oral substitution treatment of injecting opioid users for prevention of HIV infection. J Assoc Nurses AIDS Care. 2017;28(5):832-833. doi:10.1016/j. jana.2017.05.009.

6. Wish ED. U.S. drug policy in the 1990s: insights from new data from arrestees. Int J Addict. 1990;25(3A):377-409. doi: $10.3109 / 10826089009071049$.

7. Ekhtiari H, Noroozi A, Farhoudian A, et al. The evolution of addiction treatment and harm reduction programs in Iran: a chaotic response or a synergistic diversity? Addiction. 2020;115(7):1395-1403. doi:10.1111/add.14905.

8. Khammarnia M, Ansari-Moghaddam A, Peyvand M, Setoodehzadeh F. Role of Substance Abuse Treatment Centers in Addiction Recurrence. Int J High Risk Behav
Addict. 2019;8(4):e91864. doi:10.5812/ijhrba.91864.

9. Naqavi MR, Refaiee R, Baneshi MR, Nakhaee N. Analysis of gap in service quality in drug addiction treatment centers of Kerman, Iran, using SERVQUAL model. Addict Health. 2014;6(3-4):85-92.

10. Parvaresh N, Kheradmand A, Darijani M. The effect of methadone maintenance therapy on harm reduction in opiate dependents in Kerman socio-behavioral consulting centers. Addict Health. 2010;2(1-2):26-28.

11. Etebarian A, Moshref Javadi M, Kivanmanish M. Developing a health-centered sustainable development model with emphasis on addiction. Research on Addiction. 2019;12(50):43-66.

12. Gholami M. The impact of addiction treatment centers on preventing the returning of addicted people (the case study of Northern Khorasan province). Quarterly Journal of North Khorasan Police Science. 2018;5(17):27-46.

13. Mahdanianfar $M$, Masoudnia $H$, Yazdani Zazerani MR. The barriers to implementation of Islamic Republic of Iran policy in the prevention of addiction (1996-2016). Research on Addiction. 2019;13(51):55-70. 